\title{
The Springback Prediction of Deep - Drawing Quality Steel used in V - Bending Process
}

\author{
Peter Mulidrán ${ }^{1, *}{ }^{,}$Emil Spišák ${ }^{1}$, Miroslav Tomáš ${ }^{1}$, Vladimír Rohal| ${ }^{1}$, Feliks Stachowicz \\ Institute of Technology and Material Engineering, Faculty of Mechanical Engineering, Technical University of Košice, Slovakia \\ Rzeszow University of Technology, Powstańców Warszawy 8, 35-959 Rzeszów, Poland
}

\begin{abstract}
In the sheet metal forming processes, the material, and in this case deep drawing quality steel DC06 exhibits springback effect, which is governed by strain recovery of material after the load removal. In this contribution, numerical simulation of a bending process was performed and compared with experimental data. The springback is related to many parameters like forming conditions, tool geometry and material properties such as sheet thickness, yield stress, work hardening, strain rate sensitivity and elasticity modulus. In this work, the influence of used material parameters is evaluated. The springback effect of $V$-shaped sheet metal part made of DC06 steel, with a thickness of $0.85 \mathrm{~mm}$ was investigated. Bending angle was set to $90^{\circ}$. In the numerical simulation, Hill48 and Barlat yield criterions were used in combination with Ludwik's and Swift's hardening models. Achieved data from the numerical simulations were compared and evaluated with experimental test results.
\end{abstract}

Keywords: springback, numerical simulation, material parameters, yield criterion.

\section{Introduction}

The springback in the metal forming process refers to the change of shape which is elastically driven. Springback occurs following a sheet forming operation when the forming loads are removed from the work piece - sheet metal. It is usually undesirable, causing problems in the next forming operations, in assembly, and in the final product. These problems typically degrade the accuracy, appearance and quality of the products being manufactured. [1-2]

The Springback effect involves small strains, similar in magnitude to other elastic deformation of metals. As such, it was formerly considered a simple phenomenon relative to the large-strain deformation required for forming. Nonetheless, appreciation for the subtleties of springback in two areas has grown dramatically. In particular, high precision is needed for the large strain plastic response that directly affects the stresses in the body before the removal of external forces. The unloading, while nominally linear elastic for most cases, it can show remarkable departures from an ideal linear law. [1-5]

Accurate bending of the steel sheets requires at the design stage of the manufacturing process to consider mechanical and other properties of the sheet material, i.e., elasticity modulus, yield stress, ratio of yield stress to ultimate tensile stress and microstructure of the material [6]. The non-uniform strain state at the section of material which was exposed to bending moment can lead to the creation of residual stress after external load release. Residual stress produces springback which is developed by involuntary changes in the shape of the part after the forming operation.

The springback can be measured or expressed as springback coefficient or as springback angle. [6] A general countermeasure against springback is to design forming 
tools that expect springback compensation, but the compensation amount is a difficult matter even for experienced tool designers and manufacturing practice is still largely based on trial and error. Specific tolerances have to be made in die design so that the final stamping will fulfil the engineer's objective for both appearance and ease of assembly.

Other counter measurements against springback include for example: stiffening of stampings (use of beads or embossing), crash forming with pressure pad, or use of variable blank holder force etc. [2] Also in the industries which produce stamping, such as the automotive industry, accurate predictions of forming process, including stress-strain distribution, springback and thickness are necessary. [7] Today it is feasible to use finite element analysis (FEA) for more accurate prediction of springback effect. $[3,8]$ Finite element analysis is modern tool that can help to achieve more accurate springback predictions. [8-11]

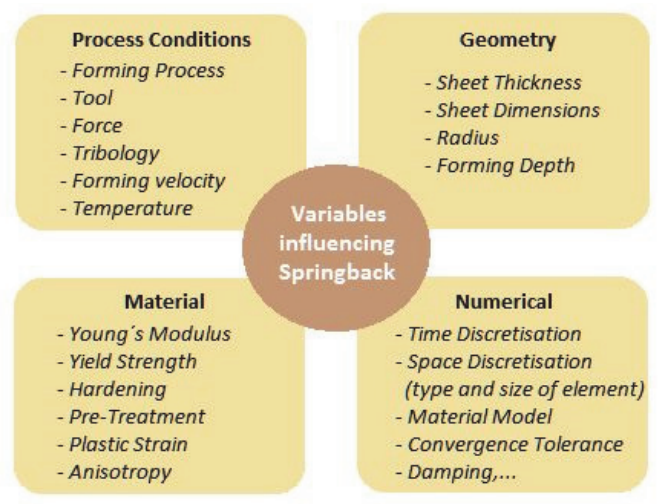

Figure 1: Variables influencing springback prediction.

In this study, springback prediction results of V-shaped part made of deep - drawing quality steel DC06, with a thickness of $0.85 \mathrm{~mm}$ were compared with experimental test results. The springback prediction has been conducted with the use of FEA, in the environment of forming simulation software. In the FE analysis of forming steel sheets, it is important to input correct process conditions, geometrical, numerical and material parameters (Fig.1). In this work, two types of yield surface models: Hill48 model and Barlat model in combination with Swift hardening model were used for springback prediction using CAE software. Also effects of bending radius $R$ [mm], calibration force $F[\mathrm{~N}]$ and planar anisotropy on springback were evaluated.

\section{Experimental procedure}

The experiment testing was conducted in the Laboratory of Testing Mechanical Properties, which is part of the Institute of Technology and Material Engineering. Measured material properties of the deep - drawing quality DC06 are shown in Table 1. Testing of material properties was done according to STN EN 10002-1, STN ISO 10274 and STN ISO 10275 standards on material test machine TIRAtest 2300. This test machine is equipped with strain gauge, longitudinal extensometer and also with a sensor which is used for measuring thinning of tensile test specimen during testing. Tensile test specimens were prepared according to STN EN 10002-1 standard.

The Bending experiments were conducted on hydraulic press ZD-40. This device also consists of the strain gauge, which was used to measure applied force. Control unit of ZD-40 collected force data, which were then transferred to PC and later processed in excel. Fig. 2 shows the bending tool (a) hydraulic press ZD-40 (b) for the experimental testing. The bending angle, i.e. the angle of working surfaces of a bending tool, was 90 degrees. Two punches with different bending radiuses $\mathrm{R}$ $\left(\mathrm{R}_{1}=1 \mathrm{~mm}, \mathrm{R}_{2}=3 \mathrm{~mm}\right)$ were used in testing.

The blank used for bending had a rectangular shape with dimensions of $90 \mathrm{~mm} \times 40 \mathrm{~mm}$. These specimens were cut $0^{\circ}$ and $90^{\circ}$ to a rolling direction. The thickness of the blank was $0.75 \mathrm{~mm}$. Blank was prepared using hydraulic shears LVD CS6/31.

Three variables, which affect springback were experimentally tested and evaluated:

\section{- bending radius $R[\mathrm{~mm}]$,}

Table 1: Mechanical properties of DC06 deep - drawing quality steel.

\begin{tabular}{|c|c|c|c|c|c|c|c|}
\hline $\begin{array}{l}\text { Direction } \\
{\left[{ }^{\circ}\right]}\end{array}$ & $\begin{array}{l}\text { Yield strength } \\
\text { oy [MPa] }\end{array}$ & $\begin{array}{l}\text { Tensile strength } \\
\text { бu [MPa] }\end{array}$ & $\begin{array}{l}\text { Young's modulus } \\
\mathrm{E}[\mathrm{GPa}]\end{array}$ & $\begin{array}{l}\text { Uniform elongation } \\
\text { A80 [\%] }\end{array}$ & $\begin{array}{l}\text { Strain hardening } \\
\text { exponent } \mathrm{n}[-]\end{array}$ & $\begin{array}{l}\text { Planar anisotropy coefficient } \\
\text { r [-] }\end{array}$ & $\begin{array}{l}\text { Poisson's ratio } \\
\text { V [-] }\end{array}$ \\
\hline 0 & 145 & 292 & 195 & 50.8 & 0,261 & 1.888 & 0,3 \\
\hline 45 & 151 & 298 & 195 & 47.9 & 0.255 & 1.464 & 0.3 \\
\hline 90 & 149 & 290 & 195 & 48.0 & 0.259 & 2.193 & 0.3 \\
\hline
\end{tabular}


- bending, calibration force F[N],

- planar anisotropyr [-].

The impacts of these three variables on springback are evaluated in the results and discussion section.
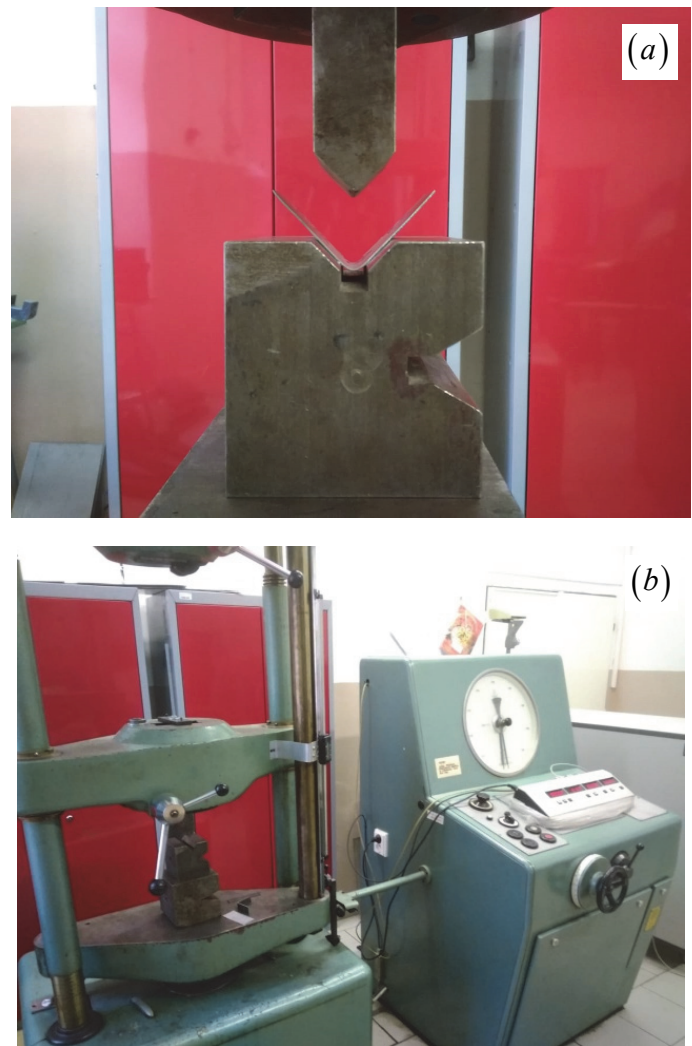

Figure 2: (a) Experimental tool used for bending, (b) hydraulic press ZD-40.

\section{Simulation procedure.}

The numerical simulations of bending DCO6 steel sheets were conducted in CAE forming software which uses special implicit method and adaptive mesh algorithms. Tool geometry is an important factor in sheet metal forming. Thus it also important to correctly model forming tools which are then used in CAE software. Imported CAD model of experimental tool, which was used in numerical simulation, is pictured in Figure 3 .

The geometry, dimensions of the CAD model of the tool were the same as in the experimental bending tool. After importing CAD model into CAE environment, the tool surfaces needed for simulation were meshed with triangular shell elements. Accuracy of the numerical simulation was

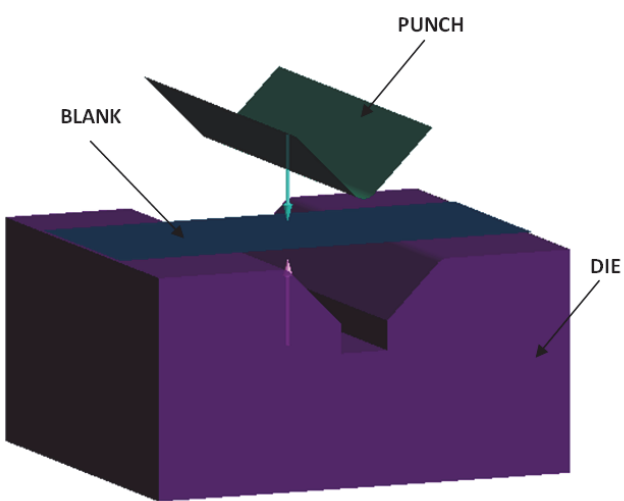

Figure 3: CAD model of the bending tool.

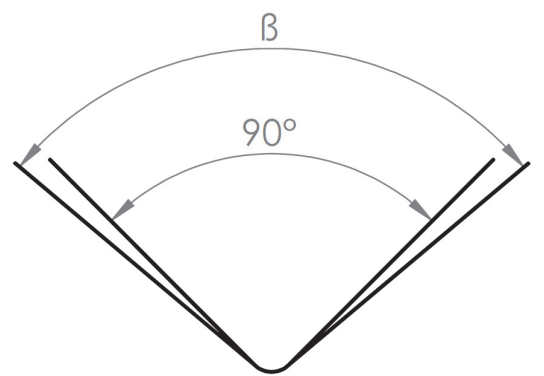

Figure 4: Measurement of springback Arm opening angle $ß\left[^{\circ}\right]$.

set to fine. With this setting, program automatically generates mesh parameters for blank. Blank also consisted of triangular elements. The initial element size of shell element was set to $3 \mathrm{~mm}$ with maximal refinement level of 2 . Radius penetration was set to 0.16 ; number of integration points was set by software to 11. The maximum time step was set to $0.5 \mathrm{~s}$ and coefficient of friction value was set to 0.27 .

The Geometry and dimensions of the CAD model of the tool were same as in the experimental tool. Accuracy of the numerical simulation was set to fine. With this setting, program automatically generates mesh parameters. Triangle elements were used in all numerical simulations. The initial element size was set to $3 \mathrm{~mm}$ with max. refinement level of 2. Radius penetration was set to 0.16 ; a number of integration points was set by software to 11 . The maximum time step was set to $0.5 \mathrm{~s}$ and coefficient of friction value was set to 0.27 . Forming speed was set to $1 \mathrm{~mm} / \mathrm{s}$.

To study the effects of material parameters on springback, Hill48 and Barlat yield criterions were used in combination with Ludwik and Swift hardening models in the numerical simulations. 


\section{Results and Discussion}

In this section, experimental results and simulations results are presented and evaluated. Experimental results of measured springback - Arm opening angle $\beta\left[^{\circ}\right.$ ] (Fig. 4) after bending process are shown in Fig. 5. The springback was measured by scanning the stamping with Canon MF4730 device. The scanned picture of stamping was then imported to CAD software AutoCAD and measured with the use of design tools. Given the results, it can be assumed, that calibration force and value of tool radius have a significant impact on the springback effect. In addition, effects of used yield criterion and hardening law on springback prediction were investigated.

The Springback results achieved using different yield criterions and hardening laws for punch radius R1 were compared with test results and pictured in Fig. 6. From the given springback prediction results,

Punch radius $\mathbf{R} 1$

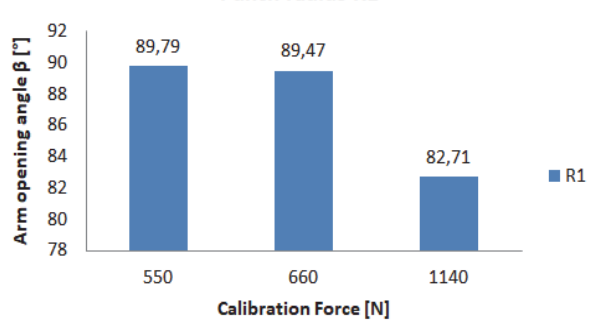

which were obtained by measuring the stampings in AutoCAD software, which were achieved from the numerical simulation, it can be assumed, that if the higher value of calibration force is used, the lower angle $\beta$ will be measured after bending, this assumption corresponds with experimental test results. The use of different combinations of material models, yield criterions and hardening laws showed different springback predictions, different values of arm opening angle $\beta$. Swift hardening law in combination with both yield criteria predicted higher values of springback after bending.

The better correlation with experimental results showed the combination of Hill and Barlat yield criterions with Ludwik hardening law, but the predicted values of springback were not identical with the experimentally achieved springback values in most cases.

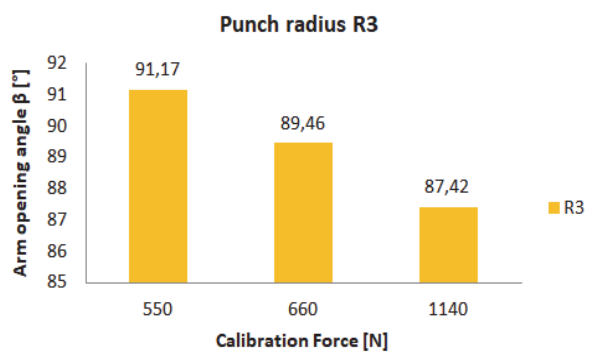

Figure 5: Comparison of measured Arm opening angle $B\left[^{\circ}\right]$ for both tested punch radiuses $\mathrm{R} 1$ and $\mathrm{R} 3$ used in the experiment.
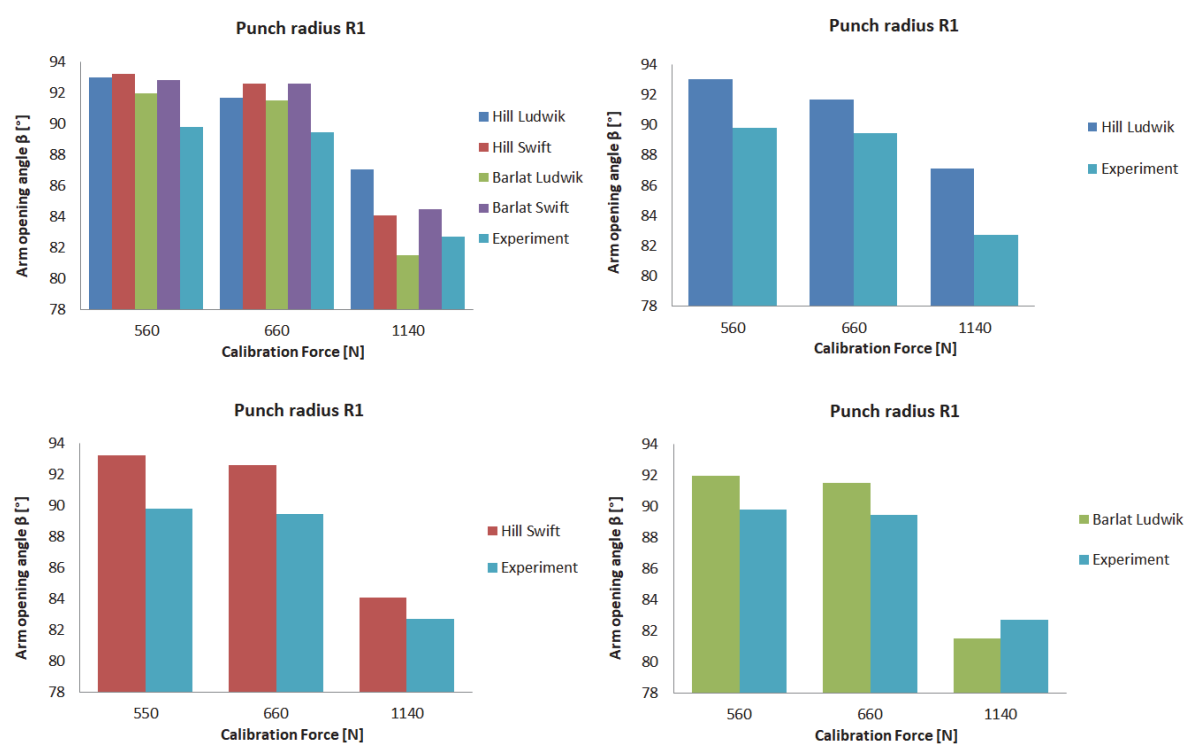

Figure 6: Comparison of predicted Arm opening angle $\beta\left[{ }^{\circ}\right]$ achieved by using different yield criterions and hardening laws in the numerical simulation. 


\section{Conclusions}

In this study, the effect of material parameters, material models on springback and its prediction of DC06 steel were evaluated. The results obtained with the use of FEA, numerical simulations were compared with experimental ones. The experimental results showed the effects of planar anisotropy, bending radius and calibration force on springback of bent DC06 steel sheet. Blanks that were cut $90^{\circ}$ to rolling direction exhibited lower springback after bending than the blanks which were cut $0^{\circ}$ to rolling direction, when punch with radius $\mathrm{R} 1$ was used. From the given experimental results, it can be assumed that if the higher calibration force is used, the lower springback will be measured after bending.

This assumption corresponds with numerical results. In the numerical simulations, a combination of different yield criterions and hardening laws was tested and their impact on springback prediction was evaluated. The results showed that the best correlation between experimental and numerical results were achieved, when Hill48 and Barlat yield criterions were used in combination with Ludwik hardening law and calibration force $F$ with the value $1140 \mathrm{~N}$ was used. The predicted values were not same as the experimentally achieved ones in most cases. The main reason for it can be attributed to different stress, strain values and strain paths which depend on material model and its inputs, which can significantly influence springback predictions.

\section{Acknowledgments}

This paper was written with the financial support of the granting agency APVV within the project solution APVV-17-0381, within the project solution ITMS2014+ 3130117594 and of the granting agency VEGA within the project solution VEGA 1/0441/17.

\section{References and Notes}

[1] Jeswiet, J; Geiger, M; Engel, U; Kleiner, M; Schikora, M; Duflou. J. "Metal forming progress since 2000", in: CIRP J Manuf Sci Technol, 13, 2-17 (2008)

[2] Banu M, Takamura M, Hama T, Naidim O, Teodosiu C, Makinouchi A." Simulation of springback and wrinkling in stamping of a dual phase steel rail-shaped part", in: J. Mater. Process Technol., 173, 173-178 (2006)

[3] Chongthairungruang, B; Uthaisangsuk, V. "Springback prediction in sheet metal forming of high strength steels", in: Materials and Design, 50, 253-266 (2013)

[4] F.J. Avellanda, et al. "Springback evaluation for TRIP 800 steel sheets by simple bending tests" in: AIP Conference Proceedings, 10, 140-147 (2012)

[5] Dai, H.L.; Jiang, H.J.; Dai, T.; Xu, W.L.; Luo,"Investigation on the influence of damage to springback of U-shape HSLA steel plates." in: J. Alloys Compd., 708, 575-586 (2017)

[6] E. Spišák, J.Slota, J. Majerníková, "The Analysis of Plastic Strain of Single and Double Reduced Tinplates", in: Chemické listy, 105, 485-487 (2011)

[7] J. Slota, M. Šiser, M. Dvorák, "Experimental and numerical analysis of springback behavior of aluminum alloys", in: Strength of Materials, 4, 93-102 (2017)

[8] Chongthairungruang, B; Uthaisangsuk, V. "Springback prediction in sheet metal forming of high strength steels", in: Materials and Design, 50, 253-266 (2013)

[9] T. Yoshida, K. Sato, K. Hashimoto, "Springback problems in forming of High-Strength steel sheets and countermeasures".in: Nippon steel technical report, no. 103, (2013)

[10] M. Samuel, "Experimental and numerical prediction of springback and side wall curl in U-bendings of anisotropic sheet metals", in: Journal of material processing technology, 105, 382 - 393 (2013)

[11] P. Mulidrán, et al. "Influence of forming method and process conditions on springback effect in the sheet metal forming simulation." in: The International Journal of Engineering and Science (IJES), 6, 62-67 (2017) 